\title{
NEW FROM SPRINGER
}

"Unlike usual introductions to logic that begin with tedious formulations of first-order languages, Poizat cuts right to the chase by commencing with the back-and-forth approach to hierarchies of local isomorphisms between relational structures. By thus showing model theory in a mathematical, rather than metamathematical, light, he aims at a wide audience. A unique book, highly recommended. Upper-division undergraduates and up." - CHOICE

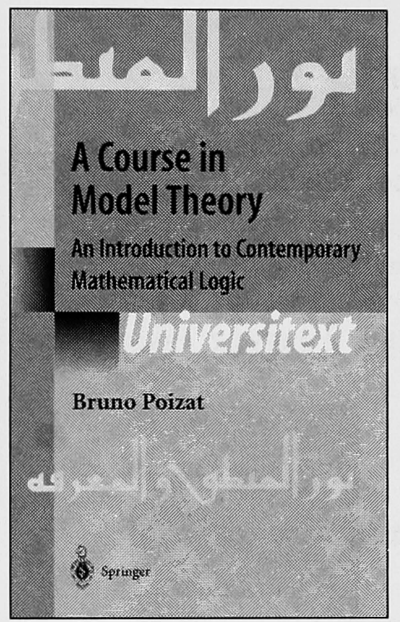

B. Poizat, Université Claude Bernard Lyon I, Villeurbanne Cedex, France

\section{A Course in Model Theory An Introduction to Contemporary Mathematical Logic}

This book, translated from the French, is an introduction to first order model theory. The first six chapters are very basic: starting from scratch, they quickly reach the essential, namely, the back-and-forth method and compactness, which are illustrated with examples taken from algebra. The next chapter introduces logic via the study of the models of arithmetic, and the following chapter is a combinatorial toolbox preparing for the chapters on saturated and prime models. The last ten chapters form a rather complete, but nevertheless accessible, exposition of stability theory, which is the core of the subject.

CONTENTS: Preface to the English Edition - Introduction - Elementary Classes of Relations - The Language Associated with a Relation - Extensions of the Language: Structures - Compactness - The Back-and-Forth Method in w-Saturated Models • Examples Illustrating the Back-and-Forth Method - Arithmetic - Ordinals and Cardinals

- Saturated Models - Prime Models - Heirs - Special Sons, Morley Sequences

- The Fundamental Order - Stability and Saturated Models • Forking - Strong Types

- Notions of Rank - Stability and Prime Models - Stability, Indiscernible Sequences and Weights - Dimension in Models of a Totally Transcendental Theory • Bibliography

- Index of Notation - Index

\section{0/464 PAGES/HARDCOVER/\$59.95/ISBN 0-387-98655-3} UNIVERSITEXT

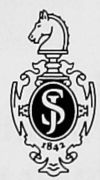

\section{Springer}

www.springer-ny.com
ORDER TODAY

AT A $\mathbf{2 0 \%}$ DISCOUNT - $\mathbf{\$ 4 7 . 9 6}$

CALL: TollFree 1-800-SPRINGER • FAX: 201-348-4505

WRITE: Springer-Verlag New York, Inc. Dept. S2550,

PO Box 2485, Secaucus, NJ 07096.2485

EMAIL: orders@springer-ny.com

YOUR 30-DAY RETURN PRIVILEGE IS ALWAYS GUARANTEED

Offer valid till December 31, 2001

$06 / 01$

PROMOTION \#S2550 


\section{T titles now available from A K Peters, Ltd.}

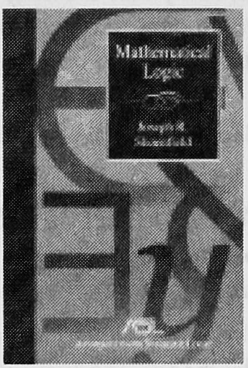

\section{A Classic Reissued}

Mathematical Logic

Joseph R. Shoenfield

2001; Paperback; 356 pp.; $\$ 35.00$

ASL member price: $\$ 28.00$

\section{From the Lecture Notes in Logic Series}

\section{Recently Reprinted}

\section{Recursion Theory}

Lecture Notes in Logic, 1

Joseph R. Shoenfield

2001; Paperback; 96 pp.; $\$ 25.00$

ASL member price: $\$ 20.00$

Logic Colloquium '90

Lecture Notes in Logic, 2 Juha Oikkonen and

Jouko Väänänen, editors

Helsinki, July 15-22, 1990

2001; Paperback; 320 pp.; $\$ 50.00$

ASL member price: $\$ \mathbf{4 0 . 0 0}$

\section{Gödel '96:}

Logical Foundations of Mathematics,

Computer Science and Physics-

Kurt Gödel's Legacy

Lecture Notes in Logic, 6

Petr Hájek, editor

2001; Paperback; 336 pp.; $\$ 50.00$

ASL member price: $\$ \mathbf{4 0 . 0 0}$

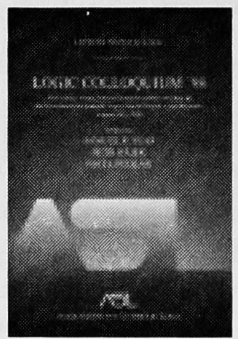

\section{Logic Colloquium '98}

Lecture Notes in Logic, 13

Sam Buss, Petr Hájek, and

Pavel Pudlák, editors

Prague, August 9-15, 1998

2000, Hardcover; 560 pp.; $\$ 85.00$

ASL member price: $\$ 68.00$

2000; Paperback; 560 pp.; $\$ 40.00$

ASL member price: $\$ 32.00$

\section{Order directly from}

A K Peters, and mention your

ASL membership to receive the ASL member price. 


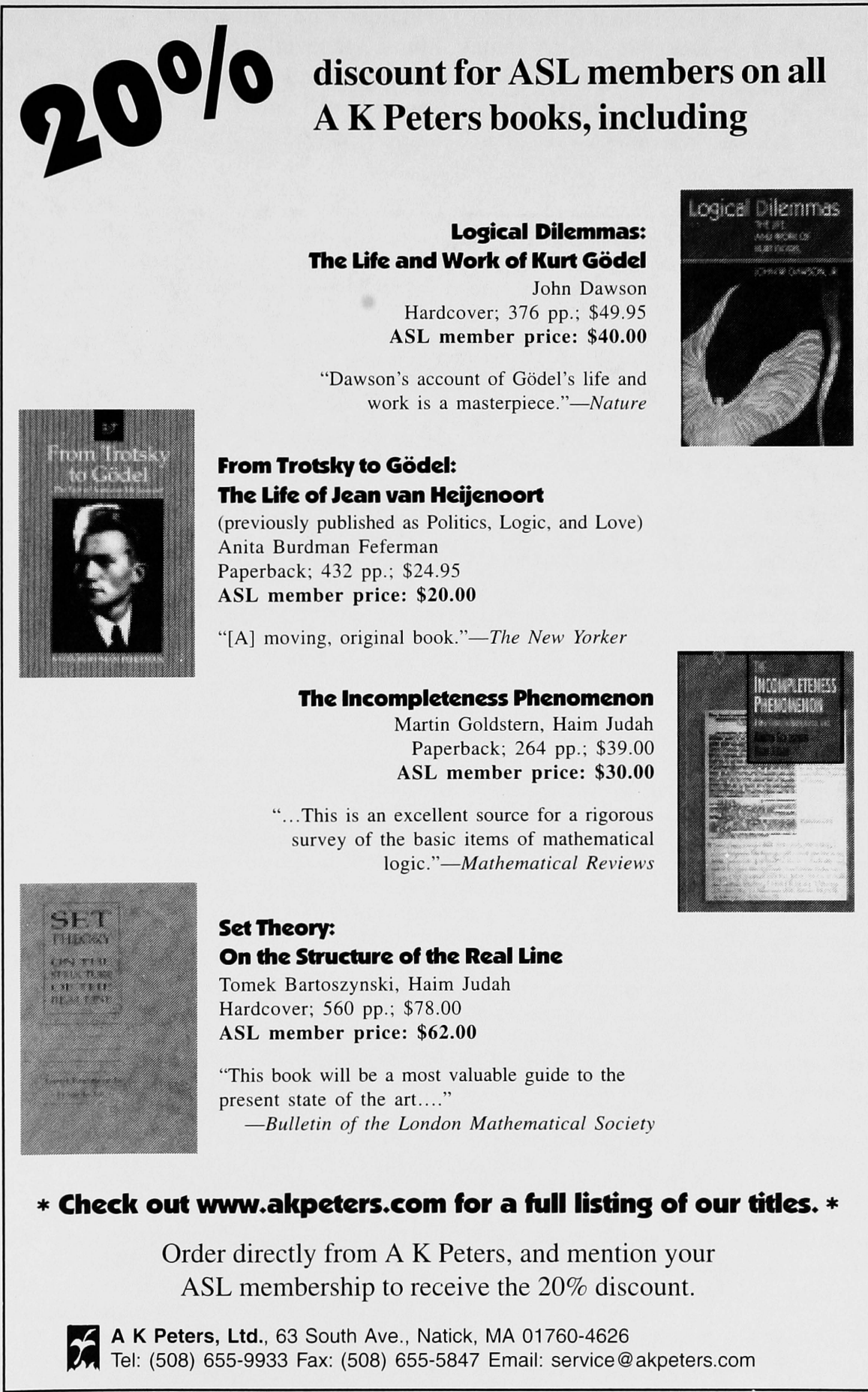


Articles should be expository or survey papers of broad interest that are accessible to a wide audience of logicians. They may deal with any areas of logic including mathematical or philosophical logic, logic in computer science or linguistics, the history or philosophy of logic, and applications of logic to other fields.

Communications should be announcements of important new results and ideas in any aspect of logic; they may be short papers in their final form or preliminary announcements (extended abstracts, position papers) of longer, full papers that will be published elsewhere. In any case, they should include, in addition to a description of the new results or ideas, enough history, background, and explanation to make the significance of the work apparent to a wide audience. Communications will be quickly refereed and published within six months of the submission of final versions.

Articles should be submitted to Andreas R. Blass, Department of Mathematics, University of Michigan, Ann Arbor, MI 48109, USA (ablass@umich .edu). Communications may be submitted to any of the other editors: John P. Burgess, Department of Philosophy, Princeton University, Princeton, NJ 08544, USA (jburgess@pucc . princeton. edu); or Alexander S. Kechris, Department of Mathematics, Caltech, Pasadena, CA 91125, USA (kechris@caltech.edu); or $\boldsymbol{H}$. Dugald Macpherson, Department of Pure Mathematics, University of Leeds, Leeds LS2 9JT, England (pmthdm@amsta . leeds . ac . uk); or Philip J. Scott, Department of Mathematics, University of Ottawa, 585 King Edward, Ottawa, Ontario, Canada K1N6N5 (phil@csi .uottawa.ca); or Richard A. Shore (Managing Editor), Department of Mathematics, White Hall, Cornell University, Ithaca, NY 14853, USA (shore@math. cornell. edu).

Books for review in the BULLETIN should be sent to Herbert B. Enderton, Association for Symbolic Logic, UCLA, Los Angeles, CA 90095-1555, USA. The other editors of reviews are Matthew Foreman (mdforema@uci.edu), Gerhard Jäger (jaeger@iam.unibe.ch), Penelope Maddy (pjmaddy@uci.edu) and Philip Scowcroft (pscowcrof t@eagle.wesleyan.edu).

Submitted manuscripts should be typewritten with wide margins and with double spacing between the lines, or prepared with a word processor, such as LTEX or Microsoft Word. Two copies of the manuscript should be sent to the editor, and the author should also keep a complete copy and the electronic file from which the submitted copy was prepared, if a word processor was used. After the paper is accepted in its final form, an electronic copy will be appreciated and will advance the final publication date of the paper, especially if it is in LTEX or $\mathcal{A} \mathcal{M S}$-LATEX. The Journal and the Bulletin of Symbolic Logic are typeset in a version of $\mathcal{A} \mathcal{M} \mathcal{S}$-LATEX, using a stylefile which is posted on the ASL Website, http://www .aslonline.org, along with instructions for its use. Fifty offprints of each article are supplied at no charge, and additional offprints may be purchased if desired.

Postscript files of articles published in the BuLLETIN may be downloaded using a Web browser from http://www. math.ucla.edu/ asl. A link to this database may also be found the ASL Website, at http://www .aslonline.org.

Individual membership in the Association is open to anyone interested in its work. Annual dues for members are $\$ 60$ ( $\$ 30$ for students). Dues include subscriptions to the current volumes of the JOURNAL and the BULLETIN. Institutional membership in the Association is available to any academic institution or department. Annual institutional dues are $\$ 525$ for 2000 . Membership privileges include choices of current subscriptions, back volumes, and student memberships. A detailed description of institutional and corporate memberships is available from the SecretaryTreasurer.

Requests for information, applications for membership, orders for back volumes, business correspondence, and notices and announcements for publication in the BULLETIN should be sent to the Secretary-Treasurer of the Association, C. Ward Henson, ASL, Department of Mathematics, University of Illinois, 1409 W. Green Street, Urbana, IL 61801, USA. The electronic mail address of the Association's business office is asl@math . uiuc.edu.

Notices of change of address, dues payments, and subscription orders to the JoURNAL and BuLLETIN should be sent to the Association for Symbolic Logic, Journals Division UIP, 1325 South Oak Street, Champaign, IL 61820-6903, USA. All orders must be accompanied by payment in US dollars; Visa and MasterCard charges are accepted. 


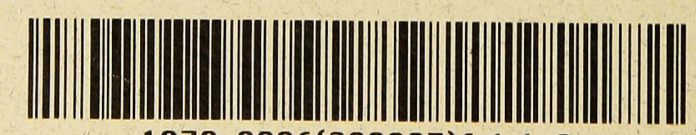

1079-8986(200003)6:1;1-G 